\title{
Reflective Teaching
}

\section{ISGHGCITAG TGSCJITI}

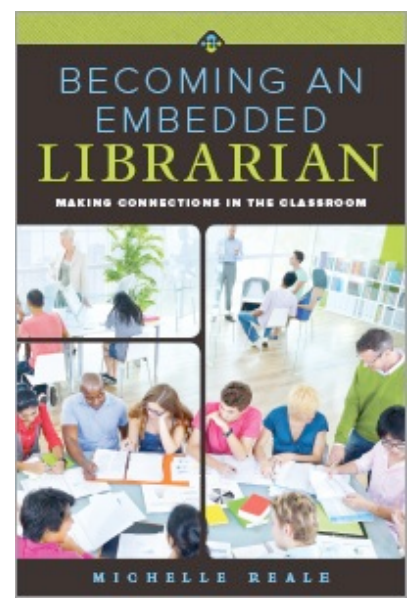

\section{Becoming an Embedded Librarian: Making Connections in the Classroom}

\author{
Reale, Michelle \\ ALA American Library Association, 2016
}

Book Review

Tags: embedded teaching | learning community librarianship

\section{Reviewed by: Brad Ost, Atlanta University Center \\ Date Reviewed: July 15, 2016}

It would be easy to become intimidated while reading Michelle Reale's book. It isn't just her wealth of practical knowledge and hard won experience that may intimidate the reader, it is the daunting nature of embedded librarianship (EL) itself. Reale writes that "embedded librarianship necessitates the stepping out of an old, comfortable role and embarking on a new way of being, without the safety net of known results" (79). Even so, setting the intimidation factor aside, there are excellent reasons to add this book to your reading list.

The author makes the most of this slim volume, a mere 104 pages, by combining both her personal journey through and scholarly support for her flavor of EL. Tucked in the middle of Reale's twelve chapters are two chapters discussing educational theory in-depth as it applies to EL. The author's theoretical foundation is based on Jean Lave and Etienne Wenger's "community of practice" model of learning. This community work constructs learning through the art of conversation. In addressing the group work that establishes a community of learning Reale writes "learning begins to take shape in community as students are encouraged to think out loud" (37). Her focus is on the librarian encouraging and mediating student communities within the classroom. This approach explains her dedication to in-person EL.

While Reale's scholarship on the application of educational theory to EL is helpful, it is her personal journey that makes this book special. Reale brings the reader along the path, mitigating neither failure nor success, allowing the individual to decide whether this journey is also for them. The book reads a bit like a suspense novel with the reader wondering whether the hero will survive the next faculty encounter or student misunderstanding. The journey is filled with practical advice including concept mapping - hand out sheets of paper with just 
circles in them to allow the students to fill in; marketing - quoting Ulla de Stricker "Marketing isn't our issue. Relationships are" (73); and personal goal setting that helps librarians visualize success.

Reale's chapters "Relationship Building," "Clarifying Your Role," "Establishing a Teaching Style," "Setting Personal Goals," and "Personal Branding" are as effective for standard librarianship as they are for EL. Consequently, even if the reader decides the EL journey is not for them the read is still worthwhile.

There was one small negative. It is not evident from the cover that the book discusses only inclass embedding. There is no discussion about online embedding which is becoming more and more relevant with the rapid growth of online education. That in itself is not negative. But this comment juxtaposing online and actual classroom embedding, "I am primarily interested in actual classroom embedding and believe it to be true embedding" (xviii), may lead some to believe Reale is a bit too chauvinistic in her approach. Her comment on one-shot instruction, "The days of one-shot instruction just don't work anymore," (8) may add weight to this opinion for those who strive to excel in online embedding or creatively moving forward with one-shot instruction. But considering the value of the rest of the work these are minor concerns.

https://www.wabashcenter.wabash.edu/resources/book_reviews/becoming-an-embedded-librari an-making-connections-in-the-classroom/ 